\title{
A metamorfose e o campo da saúde mental de trabalhadores: uma análise bakthiniana
}

\author{
The metamorphosis and the field of the mental health of workers: \\ a Bakhtinian analysis
}

Alexandre de Carvalho Castro (https://orcid.org/0000-0002-8140-3738) ${ }^{1}$

Luís Henrique da Costa Leão (https://orcid.org/0000-0003-0166-5066) ${ }^{2}$

${ }^{1}$ Centro Federal de Educação Tecnológica Celso Suckow da Fonseca. Av. Maracanã 229, Maracanã. 20271-110 Rio de Janeiro RJ Brasil.

o.aken@uol.com.br

${ }^{2}$ Instituto de Saúde Coletiva, Universidade Federal de Mato Grosso. Cuiabá MT Brasil.

\begin{abstract}
The scope of this paper is to analyze the dialogism between the narrative of Franz Kafka in "The Metamorphosis" and the discursive practices surrounding the mental health of the worker. Based on the theoretical/methodological perspective postulated by Mikhail Bakhtin, this study conducted a discursive analysis of Kafka's narrative based on the concepts of the Ergonomics of Activity and the Psychodynamics of Labor. In particular, the concepts of "dialogism" and "gender of discourse" in Bakhtin were used because they enable the study of the text and the social reality simultaneously. The results of this analysis, based on references from the field of Mental Health and Work, indicated that dialogical relations were established in two main areas: the invisibility of the suffering of the worker; and the strategy of defense and redefinition of the worker. These aspects, therefore, indicate a point of convergence between the discourse on mental health present in literature, which emerges from the work environment, and the academic knowledge that becomes imbued with these realities. The paper highlights Kafka's work as a component in a broader setting of an already established discursive practice, currently referred to as mental health and work.
\end{abstract}

Key words Workers' Health, Working Conditions, Mental Health, Literature, Kafka
Resumo Este artigo teve como objetivo analisar o dialogismo entre a narrativa de Franz Kafka em "A Metamorfose" e as práticas discursivas acerca da saúde mental do trabalhador. A partir da perspectiva teórico-metodológica pautada em Mikhail Bakhtin, este estudo desenvolveu uma análise discursiva da narrativa de Kafka frente ao conjunto de conceitos da Ergonomia da Atividade e da Psicodinâmica do Trabalho. Foram utilizados, particularmente, os conceitos de "dialogismo" e "gênero de discurso" em Bakhtin por permitirem o estudo do texto e da realidade social simultaneamente. Os resultados desta análise, com base nesses referenciais do campo da Saúde Mental e Trabalho, indicaram que as relações dialógicas se estabeleceram em dois eixos principais: a invisibilidade do sofrimento do trabalhador e as estratégias de defesa e renormatizações do trabalhador; aspectos que indicam, portanto, um ponto de convergência entre o discurso sobre saúde mental presente na literatura, o que emerge do ambiente de trabalho e os saberes acadêmicos que passam a ser tecido sobre essas realidades. O artigo destaca a obra de Kafka como uma peça num cenário mais amplo de formação de uma prática discursiva já consagrada atualmente nomeada de saúde mental e trabalho. Palavras-chave Saúde do Trabalhador, Condições de Trabalho, Saúde Mental, Literatura, Kafka 


\section{Introdução}

Os saberes e práticas em saúde mental e trabalho são cada vez mais presentes e ressaltados nos âmbitos acadêmico, institucional e social. Surgem estatísticas para demonstrar o aumento dos transtornos mentais relacionados ao trabalho, novas estratégias e pactos sociais e políticos emergem para resolver tais situações e pesquisas continuam a ser formuladas para subsidiar a compreensão e intervenção nesse âmbito ${ }^{1}$.

$\mathrm{Na}$ comunidade científica, particularmente, existe um conjunto de linhas teóricas e metodológicas sobre as relações saúde mental e trabalho. Elas partem de diferentes matizes médico-fisiológicas, psicológicas comportamentalistas, sociológicas e compreensivas, entre outras, mas têm em comum o esforço para compreender e intervir na gênese dos sofrimentos dos trabalhadores.

As abordagens mais presentes na literatura científica atual são: (a) enfoques de estresse e burnout, (b) linhagens da psicopatologia do trabalho, incluindo a vertente do desgaste mental (Saúde Mental Relacionada ao Trabalho), (c) abordagens organizacionais, (d) estudos de assédios e violências psicológicas, (e) psicossociologia e análises institucionais, (f) perspectivas da ergonomia e (g) as clínicas do trabalho, particularmente a Psicodinâmica do trabalho, a Clínica da Atividade e a Ergologia ${ }^{1}$.

Essas abordagens abrem um leque de fenômenos em saúde mental dos trabalhadores destacando-se as relações dos sujeitos com o trabalho, o que inclui dimensões afetivas e envolvimento subjetivo, vínculos simbólicos entre sujeitos e instituições, comportamentos nas organizações, sofrimentos e prazer no trabalho, desgastes mentais, da autoimagem e identidade, estressores dos ambientes de trabalho, violências organizacionais, entre outros.

Explicar a atual existência desse campo plural eivado de tradições divergentes, bem como do conjunto de informações, grupos de pesquisa, interesses públicos na área de saúde mental dos trabalhadores, exige problematizar as condições de possibilidade para a emergência desses saberes e práticas, já consolidados e institucionalizados.

Destaca-se que essas abordagens decorrem dos diferentes discursos sobre a relação saúde mental e trabalho que emergem em diferentes campos sociais na passagem dos séculos XVIII a XX. Com o despontar da modernidade e o desenvolvimento da ciência moderna surgem iniciativas de compreensão-intervenção dos aspectos ditos "mentais" do ser humano, como a Psiquiatria, a Psicologia e a Psicanálise.
As preocupações com a saúde mental dos trabalhadores, entretanto, não são exclusivas da contemporaneidade. Desde as primeiras fases do capitalismo industrial as manifestações de sofrimento entre trabalhadores foram notórias e fizeram surgir discursos na literatura, na ciência, no cinema, entre outros. Como exemplos podem ser citados: os estudos da psiquiatria de Emil Kraepelin (1856-1926) em sua "mecânica da doença mental"2 na Alemanha, a obra de Emile Zolá ${ }^{3}$ sobre a classe trabalhadora na França publicada em 1885, as análises de Max Weber sobre os efeitos físicos e psíquicos das mudanças técnicas e econômicas das condições de trabalho em A psicofisica do trabalho industrial ${ }^{4}$ publicado em 1908, as investigações de Hugo Munsterberg nos EUA e Alemanha descritos em Psychology and Industrial efficiency ${ }^{5}$ em 1913, a obra cinematográfica de Charles Chaplin, Modern Times ${ }^{6}$ de 1936, entre outras. Essas obras demonstram ampla circulação de discursos sobre problemas da classe trabalhadora, incluindo as questões relativas à saúde/ doença mental.

Dentre esses discursos, situa-se a obra $A$ Metamorfose de Franz Kafka ${ }^{7}$, escrita em 1912 e publicada em 1915, justamente no contexto da emergência de campos científicos voltados aos problemas do mundo industrial. Chama bastante a atenção o fato de personagens literários dessa obra revelarem relações dialógicas com experiências de trabalhadores e operários no tocante ao sofrimento relacionado ao trabalho.

A investigação sobre tais relações dialógicas contribui para melhor compreensão dos saberes circulantes sobre a relação saúde mental e trabalho que compuseram o conjunto dos fundamentos do desenvolvimento das práticas discursivas atualmente consagradas como "saúde mental e trabalho". Daí a particular contribuição deste estudo, dentro de um campo mais amplo de pesquisas, sobre a construção histórica do campo da saúde mental dos trabalhadores, enquanto objeto de estudos e ações no contexto da saúde coletiva.

É preciso ressaltar a existência de uma transversalidade entre o campo da ciência e da literatura, como demonstrou Canguilhem ${ }^{8}$, ao indicar relações entre o naturalismo literário e as doutrinas biológicas e médicas do século XIX. Para ele os cientistas vivem sua vida num ambiente não exclusivamente científico e, por isso, as ligações entre o discurso científico e a cultura circundante são evidentes ${ }^{8}$. Literatos difundiram concepções que se tornaram correntes e os profissionais da área de saúde, muitas vezes, são mais influenciados pelo discurso literário que pelo discurso científico: "A leitura de Littré, de Renan, de Taine 
certamente suscitou mais vocações para a medicina que a de Richerand ou de Trousseau"

Ressalta-se que a análise de textos literários ainda não é caminho trilhado frequentemente em estudos na área de saúde do trabalhador, embora seja considerada uma perspectiva promissora ${ }^{9}$. A análise de uma dada narrativa literária, sob o ponto de vista das relações entre a subjetividade, saúde e trabalho, particularmente, oferece opções enriquecedoras para a perceber as mútuas influências entre os diferentes saberes não científicos e o surgimento e consolidação de conhecimentos acadêmicos. Até porque é também imprescindível vislumbrar as relações da saúde coletiva com o mundo do trabalho como calidoscópio, constituído de uma simultaneidade de eventos, de ordem ética, social e cultural. Certamente um romance literário - como, no caso, A Metamorfose - não foi escrito com o motivo subsidiário de constituir, stricto sensu, um estudo científico. Kafka escreveu para leitores que não estavam necessariamente preocupados em apreender teorias científicas, mas seu texto guarda uma dimensão dialógica com diversas outras práticas discursivas, o que efetivamente indica a relevância dessa abordagem na configuração de um campo distinto do conhecimento posteriormente chamado de saúde mental e trabalho. $\mathrm{O}$ objetivo desse artigo é analisar o dialogismo entre essa narrativa literária e as práticas discursivas acerca da saúde mental do trabalhador, particularmente nas linhagens teóricas das clínicas do trabalho.

\section{Referencial teórico-métodológico}

Trata-se de uma pesquisa qualitativa de inspiração Bakhtiniana voltada à análise textual e sua interpretação à luz dos atuais saberes em saúde mental e trabalho. Procedeu-se aqui a análise do texto kafkiano A Metamorfose sob a perspectiva das imbricações do dialogismo com o campo da saúde mental e trabalho. Buscou-se evidenciar as práticas discursivas de Gregor Samsa (personagem literário) e os "gêneros do discurso" ${ }^{10}$ presentes nos coletivos de trabalho.

Para fundamentar a convergência entre a análise do discurso presente na literatura e o estudo do enunciado que emerge do meio social, essa pesquisa se fundamentou na perspectiva teórica de Mikhail Bakhtin. Foram utilizados os conceitos de "dialogismo" e "gênero de discurso" nesse autor por permitirem o estudo do texto e da realidade social simultaneamente. Por conseguinte, a perspectiva aqui adotada foi dialógica no sentido de possibilitar ver o texto literário em diálogo ${ }^{11}$ não apenas com outros textos, como os da produção acadêmica sobre Saúde Mental e Trabalho, mas também com o evento social da interação verbal. O discurso não foi apenas identificado com o seu conteúdo ostensivo, aquilo que é dito, mas também com o enunciado do ato social, com o que fica suposto, com tudo o que se deixa por dizer ${ }^{12}$.

Por isso, buscou-se analisar como Kafka tratou o discurso do narrador e de seus personagens, assim como os personagens literários trataram o discurso uns dos outros. Ao mesmo tempo, considerou-se o quanto tais enunciados são análogos aos processos discursivos do mundo do trabalho.

A incorporação de Bakhtin no campo de estudos do trabalho, cabe ressaltar, tem proeminência no âmbito das abordagens clínicas do trabalho, particularmente na própria Clínica da Atividade - abordagem teórico-metodológica convergente ao conjunto de conceitos da Ergonomia da Atividade, da Psicodinâmica do Trabalho e da Ergologia.

As clínicas do trabalho são um conjunto de abordagens sobre a situação de trabalho que têm em comum a noção de trabalho como atividade ${ }^{1}$. A escolha dessas perspectivas nessa pesquisa deuse exatamente pela sua pertinência em relação à discussão do papel da linguagem e dos gêneros discursivos nas suas análises dos fenômenos do mundo do trabalho.

Pesquisadores que compartilham as premissas da Clínica da Atividade avaliam a contribuição de Bakhtin em termos de uma mudança de paradigma em relação aos procedimentos até então usuais ${ }^{13,14}$. Tal transformação implicou uma refutação da atitude reducionista pela qual a linguística formalista restringia seu campo de análise, pois na visão bakhtiniana o caráter principal do sentido do discurso é a sua constante metamorfose.

Ainda que sem incorporar a literatura e se detendo principalmente na fala de trabalhadores, os aportes bakhtinianos têm sido sobejamente adotados nos estudos sobre saúde do trabalhador - vide o caso da Ergologia - mormente por influência de linguistas como Daniel Faïta, para quem a análise da atividade demanda um olhar mais amplo que incorpore também análises discursivas $^{15}$.

A ideia é que os desenvolvimentos históricosociais produzem um movimento de circulação do discurso, onde se dá uma evolução temática na qual o sentido das palavras, noções e conceitos se reconstituem continuamente. $\mathrm{O}$ enunciado 
dirigido a um dado interlocutor dirige-se, na verdade, à maneira pela qual os sentidos múltiplos circulam na consciência dele. Discursos variados modulam mutuamente a amplitude históricosocial de construção do sentido, através de processos que estabelecem respostas para as questões levantadas anteriormente por outras vozes, em outros momentos e em outros lugares. Dessa forma, enunciados produzidos em um domínio de atividade idêntica, ainda que por diferentes sujeitos individuais, apresentam traços recorrentes que uma vez relacionados dentro de um grupo social homogêneo constituem um "gênero de discurso"10 ${ }^{10}$ uma forma comum de pensar e falar.

O pensamento em perpétua evolução, construído no fluxo da interação social em âmbitos de atividade variados dá instrumentos e recursos aos diversificados grupos sociais para explicitarem seus valores e concepções nas situações cotidianas singulares que enfrentam. De fato, cada grupo possui um repertório de formas de discurso que assume a função de um espelho no interior da vida em sociedade, pois reflete e retrata o dia a $\operatorname{dia}^{13}$.

Esses instrumentos discursivo-sociais construídos, adaptados e aperfeiçoados pelos grupos na perspectiva bakhtiniana são designados como "gêneros do discurso". Um conceito que possui um espectro abrangente e inclui a conversa corriqueira, os relatos jornalísticos, as prescrições médicas, as determinações legais e até os gêneros literários clássicos (romance, poesia, etc) ou a pesquisa científica.

Esses gêneros não se dimensionam univocamente, mas configuram diálogos. Por isso é importante sublinhar outro conceito central em Bakhtin ${ }^{11}$ - o "dialogismo" - que pressupõe o fato da prática discursiva fazer parte de um processo de comunicação ininterrupto. Essa dinâmica dialógica se refere à comunicação tanto entre pessoas quanto entre textos e grupos sociais. Assim, o discurso presente em uma obra literária determina-se tanto de fora (extrinsecamente) quanto de dentro (intrinsecamente), sem que haja fronteiras rígidas entre uma coisa e outra. As diversas esferas da vida social carregam para dentro do texto seus gêneros discursivos ao mesmo tempo em que se desenvolvem, modulados pela linguagem, os condicionamentos imanentes à própria literatura.

Esses limiares extrínsecos e intrínsecos não podem ser fixamente definidos, pois o interior sempre se torna exterior e vice-versa. Torna-se necessário então esclarecer que não é o caso de se interpretar a relação entre literatura e realidade extraliterária como absorção unilateral de uma pela outra. O que ocorre é uma intermodulação: o discurso literário vê sua imagem refletida no espelho do mundo social e/ou a realidade circundante observa seu retrato no enunciado textual. Dessa forma, a metodologia aqui utilizada deriva da sugestão bakhtiniana de um processo dialógico através do qual o extrínseco e o intrínseco trocam constantemente de lugar.

Essa troca mútua deriva de uma noção de linguagem como criação coletiva, como parte de um diálogo cumulativo entre o "eu" e o outro. Já que tal "eu" não é uma ilha fechada em si mesma, ele existe em decorrência do diálogo com outros "eus". Essa concepção leva a um panorama de comunicação dialógica entre muitos "eus" e muitos "outros". Bakhtin permite, portanto, uma perspectiva transdisciplinar entre ciências humanas e a produção literária, pois o dialogismo tende a romper as linhas limítrofes entre disciplinas já que pode englobar concomitantemente aquilo que seria textual, intertextual e contextual.

Uma vez que não é possível dissociar os mecanismos textuais dos processos sociais, verificase que o texto pressupõe um interlocutor concreto e a comunicação - o diálogo - como processo de auto-compreensão através da alteridade.

$\mathrm{O}$ "eu" bakhtiniano não é um objeto monolítico concebido como essência, mas fundamentalmente metamorfose. O discurso literário é um dos dispositivos que viabilizam o eixo onde a especificidade da experiência individual eventualmente troca de lugar com a auto-experiência de outros. Ou seja, a identidade social eventualmente se transmuda pela capacidade de conceber concomitantemente tanto o "outro" como sujeito e o "eu" como objeto quanto delinear um quadro inverso ao mesmo tempo. Por isso, na análise efetuada destacou-se o quanto a identidade social dos trabalhadores também se configura como "metamorfose ambulante"16. Essa noção põe em destaque o trabalhador e a saúde mental enquanto desenvolvimento sócio-histórico. Processo esse que jamais deve ser tomado como um dado neutro e natural, uma vez que se configura em termos bastante instáveis e conflituosos ${ }^{17}$. Os desenvolvimentos históricos no mundo do trabalho não foram lineares, ao contrário, mostram etapas que derivam da cooperação entre artesãos, passam pela manufatura e atingem a grande indústria. O advento do Capitalismo Industrial, particularmente, estabeleceu novas condições de compra e venda da força de trabalho que, no âmbito da saúde do trabalhador, assumiu formas de controle ainda mais perversas ${ }^{18}$. Daí o aporte dos 
teóricos e abordagens em Saúde Mental e Trabalho - particularmente as clínicas do trabalho - se caracterizarem pela preocupação com a historicidade dos processos presentes em situações de trabalho. Nesse ramo, a gênese do sofrimento dos trabalhadores, por exemplo, é compreendida em suas relações intrínsecas com a organização prescrita e real do trabalho e suas regras, normativas e impedimentos. O reconhecimento do trabalhador, a construção e as transformações em sua identidade, as dinâmicas do sofrimento-prazer são produzidas historicamente e inscritas na história do ofício e nos modos de divisão de tarefas e pessoas nas situações de trabalho.

\section{Resultados e discussão}

Em A Metamorfose, $\mathrm{Kafka}^{7}$ apresenta um personagem - Gregor Samsa - que, numa certa manhã, ao acordar, encontrou-se transformado em um grande inseto. As razões para tal circunstância sequer são explicitadas. Não há descrição de cenários, antecedentes cronológicos, nem considerados quaisquer; pura e simplesmente o leitor é informado, na primeira frase da narrativa: $\mathrm{O}$ trabalhador acordou metamorfoseado em inseto.

Em ritmo claustrofóbico, Kafka vai gradativamente narrando a dificuldade do inseto para sair da cama, se virar no chão, alcançar a maçaneta, abrir a porta, sair do quarto... A ideia recorrente em toda a narrativa é que, ao metamorfosear-se, Samsa tinha a percepção de que "deslocava-se tão devagar"7.

Tal lentidão, no entanto, contrastava com a rapidez dos ponteiros do relógio. Ele devia ter acordado às quatro horas, mas já era um quarto para as sete. A metamorfose kafkiana não se dá em um hiato temporal, mas em um recorte sócio -histórico específico em suas demandas decorrentes. $\mathrm{O}$ enquadramento busca o cotidiano do mundo do trabalho, pois Gregor Samsa era um vendedor viajante que, de acordo com as determinações de seu patrão, precisava ter embarcado no trem das cinco horas.

Para pegar o trem das sete horas tinha que apressar-se bastante, mas sentindo "uma espécie de entorpecimento"7 não conseguiu sair da cama. Essa sua tarefa impossibilitada implicou em uma “perda do poder de agir". Essa inatividade imposta é tão importante quanto a atividade proprimamente dita, uma vez que a inatividade é causa importante de psicopatologia social ${ }^{19}$.

O tempo passou e o chefe foi atrás dele. Nessa altura da narrativa, o diálogo que Samsa desenvolve consigo mesmo evidencia o "gênero discursivo" bakhtiniano presente na relação patrão-empregado: "Que destino! Ser condenado a trabalhar para uma firma, na qual a mínima omissão suscitava imediatamente a mais grave suspeita! Seriam todos os empregados de uma organização nada mais que patifes?"7.

A dinâmica prevalecente gira em torno de explicações e implicações. O que se tem, nesses diálogos representados dentro da narrativa, é reapresentação de um gênero primário (enunciados típicos, e relativamente estáveis, de conversas entre empregadores e seus funcionários) num gênero secundário (o romance kafkiano): "Por que não compareceu ao trabalho?”-É a pergunta implícita à visita de seu chefe em sua casa:

Não teria sido realmente suficiente mandarem um auxiliar qualquer para perguntar - caso de qualquer forma achassem necessário - e seria imprescindivel a presença de seu próprio chefe, para demonstrar a toda família, uma família inocente - que aquela circunstância duvidosa não podia ser investigada por alguém menos familiarizado com os negócios da firma a não ser ele?7.

Samsa não vislumbrou explicações possíveis, apenas implicações prováveis: Será demitido. Todos os membros de sua família percebem os riscos da situação. Daí a intervenção da mãe: “O rapaz só pensa no trabalho (...) há oito dias que está aqui não tendo saído em nenhuma delas. Costuma sentar-se nessa mesa para ler o jornal ou consultar o horário dos trens"7. O discurso do chefe, porém, possui um lugar privilegiado em decorrência de seu papel social. Gregor Samsa trabalhava a fim de pagar dívidas antigas da família para com o seu patrão. O fato de a conversa transcorrer no seio da família no interior da casa certamente deixava Gregor mais fragilizado e pressionado:

$\mathrm{Na}$ posição de seu chefe peço lhe com certa energia para que me dê imediatamente uma explicação. O Senhor deixa me surpreso, sim, surpreso. Julgava-o uma pessoa sensata e digna de confiança, e agora de repente parece inclinado a exibir-se de um modo bastante deplorável. O diretor deu-me a entender esta manhã que desejava uma explicação lógica para seu desaparecimento - e isto referia-se aos pagamentos em dinheiro que lhe foram confiados recentemente. Ademais sua situação na firma não é assim tão inexpugnável. Vim até aqui com a intenção de falar-lhe tudo isto em particular, mas uma vez que desnecessariamente está desperdiçando meu tempo, não vejo bem porque seus pais não devam ouvir o que tenho a dizer. Já há algum tempo que seu trabalho tem sido insatisfatório ${ }^{7}$. 
Uma análise pautada na relação dialógica permite constatar que os personagens de A Metamorfose desenvolvem para si sistemas de transcodificação variados, a partir de gêneros discursivos distintos. Esses sistemas impõem a contingência de dialogarem pelo menos em dois planos ${ }^{9}-$ si- $^{-}$ multaneamente extrínsecos e intrínsecos - a partir daquilo que se diz e do que se pensa (o que remete à metalinguagem). Gregor Samsa tinha não só uma visão de si mesmo - um inseto - mas também uma percepção de que se relacionava com o chefe a partir de um plano assimétrico e de um nível inferior:

Se eu não tivesse que sustentar esta situação por causa de meus pais, há muito tempo que teria pedido demissão, e dirigindo-me ao meu chefe, ter-lhe-ia dito o que penso dele. Ah!, isto faria com que caísse daquela mesa. Esta é outra coisa também bastante singular, sentar-se a uma mesa e por cima dela dirigir-se aos empregados que ficam num plano inferior, principalmente quando são obrigados a aproximar-se mais, porque o chefe é meio surdo ${ }^{7}$.

Em função das práticas discursivas serem o instrumento através do qual as pessoas se posicionam no contexto das relações sociais e em decorrência do fato de o trabalho racionalizar a linguagem há uma fluência que se vincula ao sofrimento no trabalho pelo dialogismo operado na narrativa. A discussão de Kafka permite ressaltar certos pontos fundamentais para a saúde do trabalhador: A invisibilidade desse sofrimento e o recurso à doença como estratégia de defesa.

\section{A invisibilidade do sofrimento do trabalhador}

O contraste visível/invisível atravessa a narrativa de Kafka desde que Samsa é transformado em inseto. Em um momento inicial, a porta do quarto está fechada e sua família não pode ver o que ocorrera com ele. Preocupados, batem na porta, pois desejam saber o que está acontecendo: - "Entretanto, ele não estava pensando em abri-la, e sentiu-se grato por ter adquirido durante suas viagens o hábito prudente de trancar as portas à noite, até mesmo em casa"7.

Quando da chegada do chefe, a pressão para que a porta seja aberta aumenta: - "Gregor - disse o pai à porta do lado esquerdo - seu chefe veio pessoalmente e deseja saber porque você não tomou o primeiro trem. Não sabemos informá-lo. Além do mais quer falar com você, abra a porta por favor"?.

Abrir ou não a porta, segundo o narrador, torna-se uma decisão de vida ou morte. A porta fechada era uma segurança para Samsa, pois contribuía para que se sentisse menos exposto diante do chefe. A exposição de trabalhadores frente ao controle de seus superiores hierárquicos é um tema recorrente em estudos de Saúde Mental no Trabalho. Principalmente porque pressões e vigilâncias por parte da chefia podem configurar assédio moral interpessoal e organizacional, conforme análises de problemas de saúde e adoecimento de trabalhadores ${ }^{20}$.

A questão é indagar até que ponto as exigências de controle no trabalho podem ser compatíveis com a demanda pela saúde mental. Samsa falou de si mesmo em termos de evidente sofrimento. Descreveu o sentimento de "uma consciência atormentada a ponto de ficar com as ideias transtornadas"7 e por isso mesmo sentiuse incapaz de sair da cama na ocasião. A porta do quarto de Gregor Samsa metaforicamente regula o mundo interno de um trabalhador que se sente desumanizado e o mundo externo onde o Capital reitera sua prática de subordinar a si a força de trabalho ${ }^{21}$. A decisão de abrir ou não a porta evidencia a fragilidade de alguém obrigado a ampliar a extensão do domínio da autoridade de outrem sobre sua própria vivência subjetiva. A atitude de abrir ou não a porta ressalta a fraqueza de quem é constrangido a diminuir o limite que separa o seu mundo subjetivo interno do controle objetivo externo.

De um lado da porta temos o chefe que deseja "ver" uma justificativa plausível: "Espero que não seja nada grave. Embora por outro lado, deva declarar que nós, os homens de negócio - felizmente ou infelizmente - várias vezes somos simplesmente obrigados a ignorar qualquer indisposição ligeira, pois a obrigação tem que ser considerada antes de tudo"7.

Do outro lado está um trabalhador acuado em um paradoxo existencial que tanto se expõe ao se esconder (posto que fica passível de uma demissão), quanto se esconde ao se expor (uma vez que escamoteia sua condição). A narrativa kafkiana evidencia nitidamente a ambiguidade: "E uma vez tendo que empurrá-la [a porta] para a frente continuou ainda invisível quando ela se abriu"'.

A atitude de abrir a porta se escondendo atrás dela ressalta o sofrimento dos que não conseguem estar à altura das exigências dos modelos de gestão e das imposições do ritmo de trabalho. Esse sofrimento não se vê, conforme salientou Dejours $^{22}$, para quem a visibilidade não contempla a dor, por ser o essencial da subjetividade da "categoria do invisível"22. 
Em dado momento todos viram que Gregor não mais agregava a si a condição humana. Mesmo com a situação da metamorfose desvelada a dinâmica da visibilidade/invisibilidade permaneceu no decorrer da narrativa. No dia a dia, quando sua irmã entrava no aposento para limpá-lo ou mesmo levar comida Samsa se escondia parcialmente embaixo do sofá. Posteriormente, a estratégia de invisibilidade ficou mais sofisticada. Ele se cobria com uma colcha e optava continuamente pela penumbra. Tratava-se de uma estratégia de defesa porque percebia a nocividade do meio.

Esse trabalhador que virou inseto só se torna visível se quiser. Ele pode controlar a maçaneta da porta do quarto, se esgueirar para debaixo do sofá, cobrir-se com a colcha. Atualmente, com a utilização de controles digitais no local de trabalho, a prerrogativa da invisibilidade não mais ocorre. Os desenvolvimentos tecnológicos permitem às chefias verem através da porta fechada ${ }^{23}$.

Os avanços da microinformática possibilitam um controle até há bem pouco tempo totalmente impensável sobre o trabalhador ${ }^{24}$. Seu tempo de trabalho efetivo, seu descanso, a quantidade de trabalhos realizados e a qualidade efetiva do produto final são digitalmente aferidos. $\mathrm{O}$ ambiente de trabalho "mais humano" abriga o trabalhador, mas também o obriga.

No contexto do trabalho, a memória do computador, por exemplo, pode armazenar informações as mais diversas acerca de seu usuário. Os números de acessos ao terminal, os processos desenvolvidos, a quantidade de erros, nada escapa ao registro em bytes. $\mathrm{O}$ trabalhador é controlado e se torna vulnerável. A repressão se torna mais sutil e perversa, pois não é mais a empresa que reclama dizendo que o indivíduo trabalha pouco, mas o controle informatizado e estatístico de processos é quem comprova o fato. $\mathrm{O}$ trabalho realizado se apresenta como transparente, compreensível em seus múltiplos e variados detalhes, possibilitando o conhecimento/controle por parte das organizações e empresas.

A invisibilidade do sofrimento decorre também da própria invisibilidade da atividade, pois esta jamais pode ser apreendida com a observação externa das execuções das tarefas. A atividade no essencial não se vê.

\section{Estratégias de defesa e renormatizações do trabalhador}

Dejours $^{22,25}$, assim como parte dos estudos desenvolvidos a partir da década de 1990 no âm- bito da "Psicodinâmica do Trabalho", aponta para uma distinção entre "organização do trabalho" e “condições de trabalho". Enquanto esta é responsável principalmente pelo dano à saúde física do corpo do trabalhador aquela tem efeitos psíquicos. As repercussões na dimensão subjetiva se dão porque a atividade envolve incríveis somas de mobilização pessoal, inteligência corporal e sabedoria prática por parte de cada trabalhador, em termos de engajamento. Com frequência ocorre ainda uma adaptação a riscos ocupacionais que engendram dinâmicas coletivas de defesa contra sofrimento decorrente do trabalho.

Um elemento importante a destacar é que a recorrência ao discurso da doença é efetivamente discurso frequente no contexto do mundo do trabalho. Essa tendência tem a mesma direção nessa obra kafkiana.

Gregor Samsa explicitava seu sofrimento descrevendo uma organização do trabalho com pouco dimensão coletiva em termos de apoio social, amizades, relacionamentos, por isso mesmo, pior que uma tarefa rotineira:

Meu Deus!, pensou ele, que trabalho estafante é o meu! Viajando um dia sim o outro não. É muito mais irritante do que fazer os serviços rotineiros de escritório, e ainda por cima o aborrecimento das constantes viagens, a preocupação das baldeações, as refeições precárias e irregulares, as amizades casuais, sempre novas, mas que nunca se tornam intimas ${ }^{7}$.

Ainda que não seja o caso de se conjecturar uma narrativa autobiográfica é importante assinalar que o próprio Kafka conhecia bem essas contingências. Ao trabalhar em uma Companhia de Seguros ele se deparou com a realidade de parcos salários, turnos intermináveis de trabalho e horas-extras não remuneradas ${ }^{26}$. O paralelo entre as expectativas em relação à auto realização e o sentimento de "estafa, irritação, aborrecimento e preocupação" do personagem kafkiano, para além de uma visão reducionista sobre o sofrimento, chama também a atenção para a questão do uso de si pelo trabalhador, conforme acepção de Schwartz ${ }^{26}$.

Todo trabalho é sempre uso de si, embora possa existir tanto o uso de si por outros (que vai desde as normas econômico-produtivas até as instruções operacionais), quanto o uso de si por si (que revelam os compromissos para consigo mesmo ${ }^{27}$. Essa concepção viabiliza ressaltar as contingências que afetam o engajamento das pessoas e do psiquismo nas transformações do trabalho, assim como as formas patológicas recorrentes. 
No caso do uso de si pelos outros, vivenciado intensamente por Gregor Samsa, as disputas em torno do sentido da doença são frequentes:

Supondo-se que alegasse uma doença? Isto, porém seria muito inoportuno e duvidoso, uma vez que durante seus cinco anos de emprego não estivera doente nem sequer um dia. E certamente seu superior apareceria acompanhado pelo médico da Companhia de Seguros, censuraria seus pais pela preguiça do filho e não se daria ao trabalho de ouvir qualquer desculpa, dirigindo-se diretamente ao médico, o qual evidentemente considerava toda humanidade como sendo uma simuladora perfeita de enfermidades ${ }^{7}$.

O discurso do personagem kafkiano mantém íntima relação dialógica com a fala de muitos trabalhadores para os quais realmente há associação entre doença e vagabundagem ${ }^{28}$. Há muitas vezes, por parte do mundo do trabalho, uma atribuição social vergonhosa ao trabalhador doente como um simulador de enfermidades.

Dejours ${ }^{25}$ também verificou que a ideologia da vergonha, imposta pelos patrões, se concretiza no momento em que os trabalhadores se envergonham e se culpam diante da doença, de um imprevisto, de um acidente. A análise feita pelo próprio trabalhador é frequentemente marcada pelo medo da demissão e, consequentemente, do desemprego:

"Refletiu que o fato de ter que acordar cedo tornara as pessoas estúpidas. Um homem necessita de sono. Outros negociantes vivem tal qual mulheres num harém. Por exemplo, quando em qualquer uma das manhãs estou voltando para o hotel a fim de anotar os pedidos que já recebi, aqueles estão sentando-se para tomarem a refeição matinal. Se eu fizesse isso com meu chefe, seria despedido no mesmo momento ${ }^{7}$.

A fala de trabalhadores que vivenciam o dia a dia de uma fábrica no Brasil permite constatar as relações dialógicas imersas em um mesmo "gênero do discurso", sobretudo porque indicam que enunciados tendem a se repetir diante de situações sociais semelhantes e de precarização ${ }^{29}$. É possível verificar que tanto o personagem kafkiano quanto o operário brasileiro articulam suas opções e escolhas com a possibilidade de demissão e com o desemprego:

O que eu penso é só em me aposentar. O futuro tu não... É aquilo ali, né. Não tem como pensar outra coisa. Só em me aposentar. (...) Não pensa no desemprego. Tá certo que o salário é pouco, né. (...) Mas aí tu não te preocupa em estar desempregado. Hoje em dia está ruim o emprego ${ }^{17}(\mathrm{p} .57)$.

Esses elementos da narrativa de Kafka ocorrem dentro de um recorte temático que ressalta a subordinação da força de trabalho ao Capital em que o trabalhador evidentemente se enxerga subjugado. $\mathrm{O}$ trabalhador se vê minimizado, uma vez transmudado em inseto. Não lhe restam opções: Ou alega uma doença presente ou remete para o futuro: "Depois de economizar o suficiente para pagar-lhe a dívida de meus pais - o que levará ainda uns cinco ou seis anos - pedirei sem falta minha demissão. E então sentir-me-ei completamente livre"7.

Nesse sentido, o próprio contexto produtivo condiciona a aparição e a distribuição social de enfermidades ${ }^{30}$ na classe trabalhadora e a questão da saúde/doença no mundo do trabalho possui interfaces também com as dimensões presente/ futuro e com o emprego/desemprego.

Dentro da perspectiva de saúde/doença em Canguilhem $^{8}$ que influencia fortemente a Ergologia, os fracassos e os erros também são partes constitutivas da história do trabalhador, porque obviamente a vida humana contém limitações. Consequentemente, ao contrário dos que prescrevem teses adaptativas, deve-se pensar o conceito de saúde justamente a partir da capacidade do trabalhador para enfrentar os problemas e as adversidades, as opressões e demissões. Dessa forma, a saúde não deve ser reduzida a um mero equilíbrio ou capacidade adaptativa ao meio, mas deve ser pensada em termos de uma capacidade de instaurar novas normas em situações adversas ${ }^{8,27}$.

A metamorfose do trabalhador, assim como a narrativa de Kafka, permite uma análise da saúde mental no trabalho não circunscrita aos parâmetros de equilíbrio ou conformidade com o meio social. A noção de saúde implica muito mais que a possibilidade de viver em conformidade com o mundo do trabalho. Implica a capacidade de instituir novas normas. Afinal, a atividade comporta essa dimensão renormatizadora dos trabalhadores perante as normas, sempre insuficientes da organização do trabalho.

Tal alusão a normas novas remete a uma leitura de Kafka que indica, portanto, a necessidade de outras metamorfoses. Na narrativa mesmo, curiosamente, há metamorfoses dentro de $A$ Metamorfose. A transformação de Gregor Samsa implicou mutações na família, que antes estava afastada do mundo do trabalho. A mãe passou a trabalhar costurando para uma firma de roupas de baixo; a irmã tanto arranjou emprego como balconista quanto, à noite, tornou-se estudante de estenografia e francês para assim ter uma oportunidade para melhorar de vida; e o pai começou a trabalhar como mensageiro de banco.

Após a morte de Gregor, na tentativa de tentar esquecer os últimos meses de sofrimento, a 
história termina em um passeio de bonde, fora do centro da cidade, onde a família Samsa constituía os três únicos passageiros da composição:

Confortavelmente recostados em seus assentos, examinaram as perspectivas do futuro e após uma análise mais profunda, concluíram que não eram assim tão ruins, pois os empregos que tinham conseguido, e que até o momento não tinham comentado entre eles, eram positivamente ótimos, tudo indicando que com o tempo contribuiriam para melhorar as coisas ${ }^{7}$.

\section{Considerações finais}

A análise dialógica do texto de Kafka evidenciou um "gênero discursivo" que aproxima Gregor Samsa, personagem literário, os trabalhadores hodiernos e os discursos científicos que sobre eles passam a ser tecidos no âmbito da saúde mental e trabalho.

A perspectiva bakhtiniana proporcionou um horizonte fértil de análise que ressaltou a discussão do sentido da saúde/doença mental do trabalhador assim como da (in)visibilidade de sofrimento. $\mathrm{O}$ dialogismo entre os gêneros do discurso acerca da saúde mental-trabalho e o enunciado ficcional kafkiano é evidente, visto o quanto a questão da subjetividade recebeu destaque como eixo simultaneamente extrínseco/ intrínseco ao discurso analisado a partir do texto literário. A visão bakhtiniana da construção do "eu" como metamorfose, posto que está em diá- logo cumulativo com muitos "outros", permitiu compreender a linguagem como criação coletiva, como parte de um panorama de comunicação dialógica entre muitos eus: textuais, intertextuais e contextuais. Essa análise demonstrou claramente a perspectiva transdisciplinar entre ciências humanas e a produção literária.

A obra de Kafka, portanto, permitiu ainda uma leitura crítica das relações entre subjetividade humana e trabalho. E, consequentemente, serviu de pano de fundo para a discussão de questões contemporâneas. Ademais, "A Metamorfose" viabilizou ainda passar em revista não só o próprio discurso kafkiano, mas também o gênero do discurso que conduz ao mundo do trabalho e a rede de interesses que historicamente o sustenta. $\mathrm{O}$ que se constatou foram metamorfoses de discursos marcados pela invisibilidade do sofrimento do trabalhador e pelas estratégias de defesa e renormatizações do trabalhador.

A leitura de dialógica dessas metamorfoses, entrementes, desvelou sobretudo alguns pontos de interesse para o campo de estudos da Saúde Mental e Trabalho, pois, as transformações e mudanças constituem indelevelmente o trabalhador, cuja identidade - mutável porque imersa, simultaneamente, nos processos sócio históricos das organizações produtivas - incorpora relações dialógicas das mais variadas.

Por fim, o artigo destacou o quanto essa obra de Kafka é uma peça num jogo mais amplo de formação de uma prática discursiva já consagrada atualmente nomeada de saúde mental e trabalho.

\section{Colaboradores}

AC Castro participou da concepção, delineamento, análise e interpretação dos dados, redação do artigo e revisão crítica. LHC Leão contribuiu na interpretação dos dados, redação do artigo e sua revisão crítica. 


\section{Referências}

1. Leão LHC. Vigilância em Saúde Mental do Trabalhador: Subsídios para a Construção de Estratégias de Intervenção. [tese] Rio de Janeiro: Escola Nacional de Saúde Pública; 2014.

2. Betiol MIS. Apresentação à Psicofísica do Trabalho Industrial de Max Weber. In: Weber M. A Psicofisica do Trabalho Industrial. São Paulo: Alphagraphics; 2009. p. 7-10.

3. Zolá E. Germinal. (1885). Sumaré: Martin Claret; 2006.

4. Weber M. A psicofísica do trabalho industrial. São Paulo: Alphagraphics; 2009.

5. Münsterberg H. Psychology and industrial efficiency. New York: The Riverside Press Cambridge; 1913.

6. Chaplin C. Modern Times. 87 minutos; 1936.

7. Kafka F. A Metamorfose. São Paulo: Nova Época Editorial; 1981.

8. Canguilhem G. O Normal e o Patológico. Rio de Janeiro: Forense Universitária; 2000.

9. Santos RC. Modos de Saber, Modos de Adoecer. Belo Horizonte: UFMG; 1999.

10. Bakhtin M. Os gêneros do discurso. In: Bakhtin M. Estética da Criação Verbal. São Paulo: Martins Fontes; 2000. p. 277-326.

11. Bakhtin M. Marxismo e Filosofia da linguagem: problemas fundamentais do método sociológico na ciência da linguagem. São Paulo: Hucitec; 1997.

12. Castro AC, Portugal FT, Jaco-Vilela AM. Proposição bakhtiniana para análise da produção em psicologia. Psico Estudo 2011; 16(1):91-99.

13. Souza SJ. Infância e Linguagem: Bakhtin, Vygotsky e Benjamim. São Paulo: Papirus; 1994.

14. Faïta D. A Noção de Gênero Discursivo em Bakhtin: Uma Mudança de Paradigma. In: Brait B, organizador. Bakhtin, Dialogismo e Construção do Sentido. Campinas: Unicamp; 1997. p. 159-177.

15. Faïta D. Análise das práticas linguageiras e situações de trabalho: uma renovação metodológica imposta pelo objeto. In: Souza-e-Silva MCP, Faïta D. Linguagem e trabalho: construção de objetos de análise no Brasil e na França. São Paulo: Cortez; 2002. p. 45-60.

16. Ciampa AC. Identidade. In: Codo W, Lane STM, editores. Psicologia Social: O homem em movimento. São Paulo: Brasiliense; 1999. p. 58-77.

17. Guareschi PA, Grisci CLI. A Fala do Trabalhador. Petropólis: Vozes; 1993.

18. Athayde M. Cenas a Propósito de Processos: Controle, subjetividade e trabalho. In: Silva EA, Neves CAB, Rauter C, editores. Saúde Loucura: Subjetividade. São Paulo: Hucitec; 1997. p. 157-171.
19. Clot Y. Clínica do trabalho e clínica da atividade. In: Bendassolli PF, Soboll LA. Clínicas do trabalho (6183). São Paulo: Atlas; 2011.

20. Silva EF, Oliveira KKM, Zambroni-de-Souza PC. Saúde mental do trabalhador: o assédio moral praticado contra trabalhadores com LER/DORT. Rev Bras Saúde Oсир 2011; 36(123):56-70.

21. Marcuse H. Sobre os fundamentos filosóficos do conceito de trabalho da ciência econômica. In: Marcuse H. Cultura e Sociedade. Rio de Janeiro: Paz e Terra; 1998. p. 7-50.

22. Dejours C. A Banalização da Injustiça Social. Rio de Janeiro: Fundação Getúlio Vargas; 1999.

23. Zarifian P. Engajamento subjetivo, disciplina e controle. Novos Estud CEBRAP 2002; 64:23-31.

24. Rebecchi E. O sujeito frente à inovação tecnológica. Petrópolis: Vozes; 1990.

25. Dejours C. A loucura do trabalho: estudo de psicopatologia do trabalho. São Paulo: Cortez- Oboré; 1988.

26. Hancil J. Kafka et le Métier d'Assureur. Revue Internationale de Psychopathologie et de Psychodynamique du Travail 1999; 3:193-199.

27. Schwartz Y. A comunidade científica ampliada e o regime de produção de saberes. Trabalho Educação 2000; 7(7):38-46.

28. Sawaia BB. Dimensão ético-afetiva do adoecer da classe trabalhadora. In: Lane STM, Sawaia B, organizadores. Novas Veredas da Psicologia Social. São Paulo: Educ/Brasiliense; 1994. p. 157-168.

29. Seligmann-Silva E. Trabalho e desgaste mental. O direito de ser dono de si mesmo. São Paulo: Editora Cortez; 2011.

30. Caponi S. Georges Canguilhem y el estatuto epistemológico del concepto de salud. Hist Cien Saude -Manguinhos 1997; 4(2):287-307.

Artigo apresentado em 14/02/2018

Aprovado em 10/12/2018

Versão final apresentada em 12/12/2018 